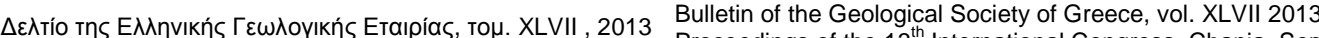
Proceedings of the $13^{\text {th }}$ International Congress, Chania Sept.

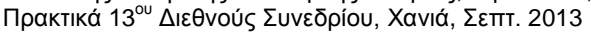
2013

\title{
UTILIZATION TRIALS OF LIGNITE SOLID BYPRODUCTS OF WEST MACEDONIA AND PELOPONNESUS LIGNITE FIRED POWER PLANTS FOR THE PRODUCTION OF LIGHTWEIGHT AGGREGATES
}

\author{
Anagnostopoulos I. ${ }^{1}$, Lampropoulou P. ${ }^{2}$, Tzevelekou Th. ${ }^{3}$, Stivanakis V. ${ }^{1}$, \\ Kastanaki A. and Papamantellos D. \\ ${ }^{1}$ University of Patras, Chemical Engineering Department \\ ${ }^{2}$ University of Patras, Geology Department, p.lampropoulou@upatras.gr \\ ${ }^{3}$ Helleninc Center of Metals Research S. A., Athens \\ ${ }^{4}$ Public Power Corporation S.A., 30 chalkokondyli St., Athens104 32
}

\begin{abstract}
The production of lightweight aggregates from the utilization of solid byproducts [fly ash (FA) and bottom ash (BA)], of the lignite fired power plants from West Macedonia (Kardia, Ptolemaida) and Peloponnesus (Megalopolis), has been investigated in this study. Sintering of FA and BA with the grate sinter band method was selected because it exploits the energy content of the raw materials for the increase of temperature and completion of the material's sintering. These byproducts contain the necessary carbon content for temperature increase during the sintering process. Detailed XRD analyses show that Megalopoli's FA contains high amounts of amorphous phase (25-54wt\%) while fly ashes from Kardia and Ptolemaida power units are more crystalline. Lime and anhydrite are the most abundant crystalline phases in Ptolemaida's and Kardia's fly ashes. The bottom ashes revealed high percentages of amorphous content (58-64wt\%) and anorthite and quartz as the major crystalline phases. Mixtures of different BA/FA ratios were prepared for sintering tests. The sintered mixtures from Kardia's and Ptolemaida's regions did not have sufficient mechanical properties for further treatment. The sintercake produced from Megalopolis' ashes exhibited good mechanical properties and was selected for further study for use as light aggregate raw materials to the lightweight concrete production.
\end{abstract}

Key words: fly ash; bottom ash, use, grate sintering, mineralogical composition.

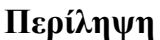

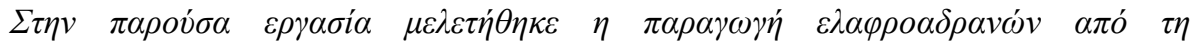

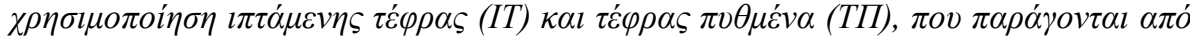

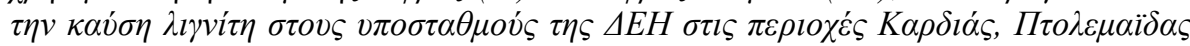

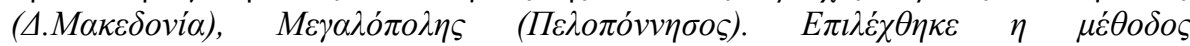

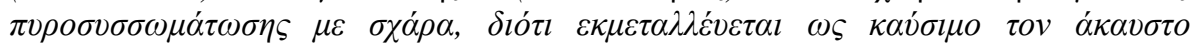

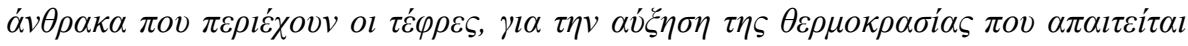

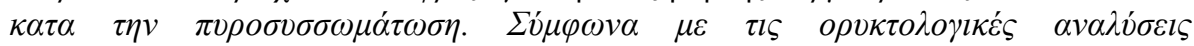

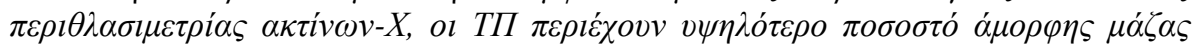

$\underline{\text { XLVII, No } 3-1600}$ 


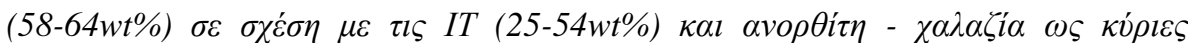

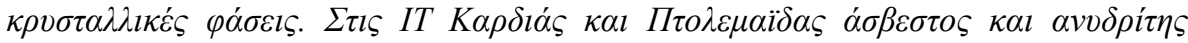

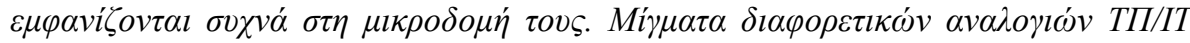

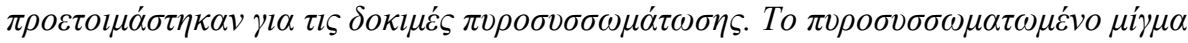

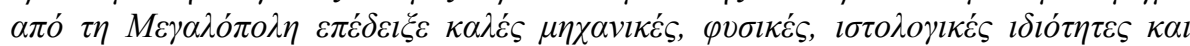

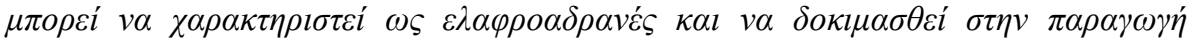

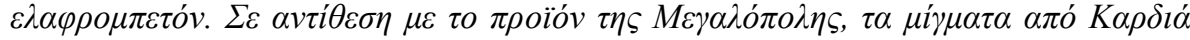

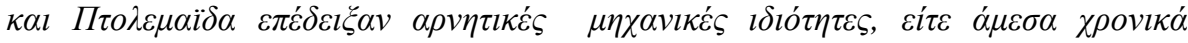

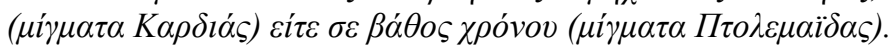

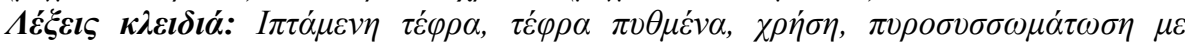

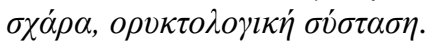

\section{Introduction}

Nowadays, the utilization of solid fuel combustion byproducts is rapidly increased all over the world, not only because of the lack of land disposal sites but for the global demand of new recycling raw materials, aiming to the combination of environmental and economic profits. The fly ash (FA) and bottom ash (BA) have been mainly found applications to the building construction, road construction or as additives in the cement or concrete (Nishigaki, 2000; Lin, 2006; Vegas et al., 2008; Anagnostopoulos et al., 2010). Many researchers have been aimed to the production of lightweight aggregates by sintering of several municipal solid wastes incineration (Bhatty and Reid, 1989; Cheeseman et al., 2005).

Lignite combustion in West Macedonia and Peloponnesus of Greece results in production of approximately $14 \mathrm{Mt} / \mathrm{year}$ of FA and BA byproducts. Today, only $10-15 \%$ of FA produced in Greece is utilized as raw material mainly in cement production while the BA use is very restricted due to its high carbon content.

This study investigates the utilization of FA and BA from the lignite fired power plants from North Greece (Kardia, Ptolemaida -West Macedonia) and South Greece (Megalopolis-Peloponnesus) as raw materials in the production of lightweight aggregates, using the grate sinter band method. This method has been applied with a lot of advantages to the bottom ash utilization (Anagnostopoulos and Stivanakis, 2009). The later contains a high carbon content which is used as the main fuel for the temperature increase during the sintering process whilst its high humidity could be utilized as the main binder phase for the agglomeration.

\section{Experimental Procedure and Analytical Techniques}

The developed process for the production of lightweight aggregates from the solid lignite combustion by-products consists of two stages, pelletization and sintering, respectively (Anagnostopoulos and Stivanakis, 2009). The whole pilot-scale sintering installation at ELKEME is shown in Figure 1. Pre -designed ratios of the solid raw materials are first mixed into a mechanical mixer and then introduced into the pelletization disc with the addition of sprayed water, if necessary. The rotating disc is of $0.6 \mathrm{~m}$ diameter and operates at a slope of $45^{\circ}$ with a rotation speed of 40-50 rpm. The formed pellets are introduced into the sinterpot, which is of $0.16 \mathrm{~m}$ surface. Five thermocouples are set up along the height of the sinterpot for the measuring of temperature inside the formed bed of pellets. A layer with charcoal of $3-4 \mathrm{~cm}$ is placed at the top of the bed of pellets, in order to assist the ignition of the pellets. The ignition of the pellets occurs the same time with the start-up of the suction blower, connected at the bottom of the pot. The blower creates suction pressure inside the pot and causes movement of the combustion zone downwards. The process of sintering is terminated when the combustion zone reaches the bottom of the pot. The flue gases of sintering are passed through a filter-bag for the removal of the solid particles. 
Chemical analyses of the studied samples (raw materials and final sintered products) was carried out in cooperation between UPATRAS (Dep. Chem. Enginnering, METLAB)-ELKEME, using AAS and ICP, while C, S contents have been measured using a Carlo -Erba analyzer. XRD analyses, using a Bruker D8 Advance diffractometer with Ni filter and $\mathrm{CuK} \alpha$ radiation, were also performed to identify the phases present in the samples, in the Laboratory of applied Mineralogy (MINTECHLAB), Department of Mineral Resources, Techn. University of Crete, Greece. In addition, quantitative analysis was performed by Rietveld Method using Rayflex Autoquan Software. Microstructures of samples have been studied in ELKEME using a FEI XL40 SFEG scanning electron microscope (SEM). The physical parameters of sintered products have been measured and evaluated according to ASTM 373-88, standards (ASTM C373-88, 2002) in the METLAB.

\section{Results and Discussion}

The raw materials BA, FA and ML (metallurgical lime) which are used for the sintering production of the final light aggregates materials are characterized below.

\subsection{Raw Materials}

\subsubsection{Chemical Analyses}

The \%wt of major oxides, carbon and LOI in the raw materials are given in Table 1. Chemical analyses of BA revealed higher percentage of loss of ignition compared with this in FA samples, due to their higher carbon content. In addition, the bottom ashes are significantly poorer in $\mathrm{CaO}$ content against to FA samples. In BA samples, the $\mathrm{SiO}_{2}$ content ranges from 37.46 (in $\mathrm{BAP}=\mathrm{BA}$ Ptolemaidas) to $41.21 \mathrm{wt} \%$ (in $\mathrm{BAK}=\mathrm{BA}$ Kardias), while the $\mathrm{Al}_{2} \mathrm{O}_{3}$ ranges from 16.27 (in $\mathrm{BAK}$ ) to 17.39 (in $\mathrm{BAP}=\mathrm{BA}$ Ptolemaidas). Fly ashes from Kardia and Ptolemaida contain significantly higher amounts of calcium oxide compared with that of Megalopolis. The maximum silicon oxide and aluminium oxide occur in FAM (=FA Megalopolis), while the minimum are contained in FAP (FA Ptolemaidas) and FAK (FA Kardias) samples respectively.

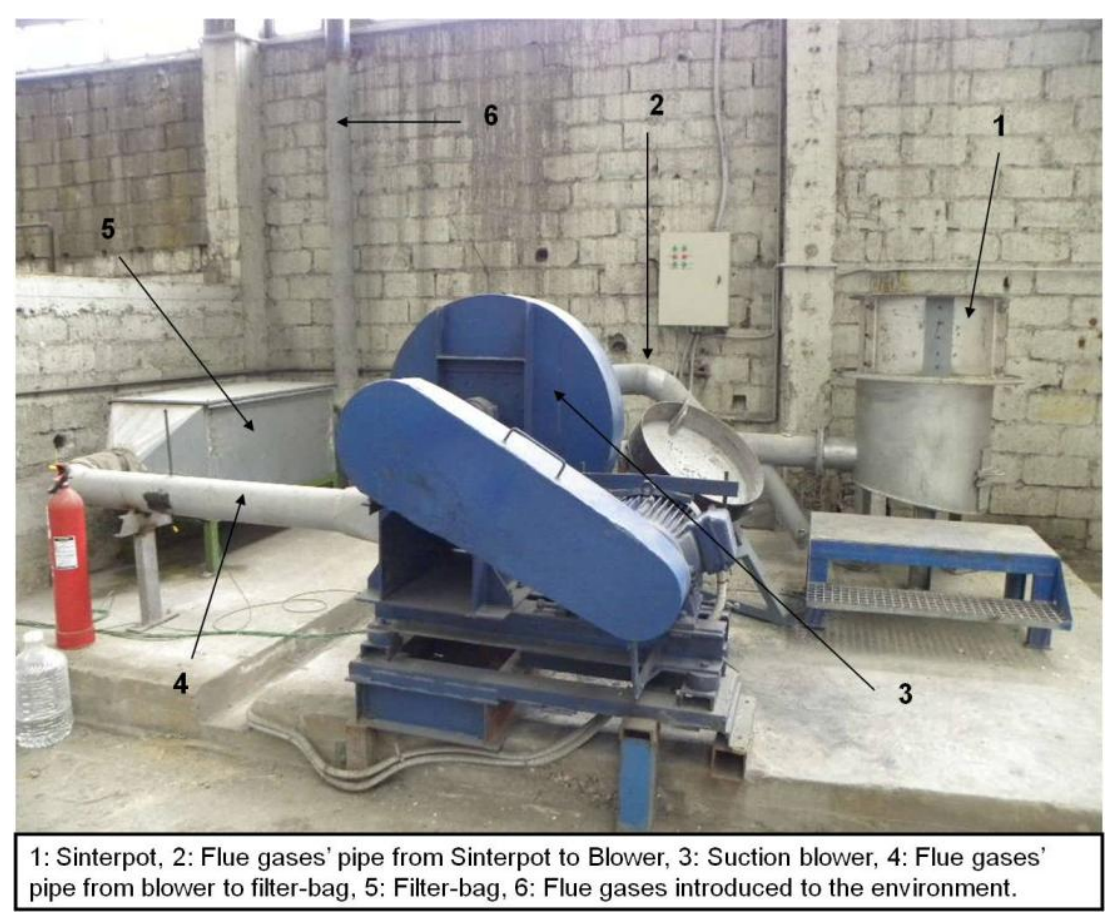

Figure 1 - Pilot-scale sintering installation.

$\underline{\text { XLVII, No } 3-1602}$ 
Table 1 - Chemical analyses (wt \%) of major oxides, C and LOI in the raw materials.

\begin{tabular}{|l|c|c|c|c|c|c|}
\hline \multicolumn{1}{|c|}{ Sample } & $\mathbf{A l}_{\mathbf{2}} \mathbf{O}_{\mathbf{3}}$ & $\mathbf{C a O}$ & $\mathbf{F e}_{\mathbf{2}} \mathbf{O}_{\mathbf{3}}$ & $\mathbf{S i O}_{\mathbf{2}}$ & $\mathbf{C}$ & $\mathbf{L O I}$ \\
\hline BAK* & 16.27 & 14.32 & 4.88 & 41.21 & 10.13 & 14.50 \\
BAP & 17.39 & 12.90 & 3.95 & 37.46 & 14.51 & 23.00 \\
BAM & 16.31 & 12.80 & 7.78 & 39.04 & 9.77 & 15.30 \\
\hline FAK & 14.60 & 33.15 & 5.63 & 29.36 & 1.64 & 4.50 \\
FAP & 15.03 & 32.55 & 6.30 & 26.36 & 1.73 & 4.60 \\
FAM & 19.27 & 14.90 & 10.68 & 46.71 & 1.22 & 1.10 \\
\hline ML & & 88.37 & & & & 11.03 \\
\hline
\end{tabular}

*Abbreviations: BAK=BA Kardias; BAP=BA Ptolemaidas; BAM=BA Megalopolis; FAK=FA

Kardias; FAP=FA Ptolemaidas; FAM =FA Megalopolis; ML: metallurgical lime

\subsubsection{XRD Analyses}

According to the XRD results, the FAM contains the higher amount of amorphous phase $(\sim 55 \%)$ while in FAK and FAP it ranges to lower percentages ( 25 to $30 \%$ respectively). In FAK and FAP samples lime and anhydrite appear as the major crystalline phases. Moreover, anorthite, quartz and gehlenite have been detected in all FA samples.

In BA samples the amorphous phase ranges from $\sim 57-64 \%$ while anorthite and quartz have been identified as the major crystalline phases. In the metallurgical lime (ML), which has been used as additive, approximately $24 \%$ of lime has been hydrated to portlandite.

\subsection{Design of Different Raw Materials Mixtures}

The ratios of the raw materials (BA, FA, ML) in the different designed mixtures prepared for sintering, are given in Table 2. Taking into account the chemical analyses of all BA samples, the mixtures of Table 2 contain the requisite carbon content used as fuel during the sintering process.

\subsection{Characterization of Final Products (pellets)}

\subsubsection{Macroscopic Characterization}

According to macroscopic observations of the sintered products those from Kardia's region did not comprise sound sinter-cake. Formation of sinter-cake (sound bonding of the pellets) is considered to be a characteristic essential visual parameter reflecting the efficiency of the sintering process. Thus, it comprises a criterion for the product's mechanical suitability for further treatment (Figure 2). Ptolemaida's mixtures (Figure 2), although they obtained the base mechanical strength after sintering, autogeneous disintegration occurred after two-three weeks later. The solid sinter cake produced from Megalopolis' ashes (Figure 2) was selected for further study for use as light aggregate raw material to the lightweight concrete production.

\subsubsection{Sintering Behaviour of Pellets}

A representative temperature-time diagram of sintering process for mixture MMEG is presented in Figure 3. Temperature $\mathrm{T} 1$ is recorded at the top of the bed of pellets and the temperature $\mathrm{T} 5$ at the bottom of the bed. The temperature T6 corresponds to the flue gases of sintering. The duration of the sintering process is approximately 50min. The temperature of sintering is between 1200 and $1250^{\circ} \mathrm{C}$. The temperature increase rate is very fast, from $600^{\circ} \mathrm{C} / \mathrm{min}$ until $1100^{\circ} \mathrm{C} / \mathrm{min}$. 
Table 2 - \% of raw materials in the different prepared mixtures for sintering.

\begin{tabular}{|l|l|l|l|l|}
\hline \multicolumn{1}{|c|}{ Name of mixture } & Origin of raw materials & BA (\%) & FA(\%) & ML(\%) \\
\hline *MMEG & Megalopolis & 90 & 7 & 3 \\
\hline MP1 & Ptolemaidas & 55 & 42 & 3 \\
MP2 & Ptolemaidas & 75 & 22 & 3 \\
\hline MK1 & Kardias & 55 & 42 & 3 \\
MK2 & Kardias & 75 & 22 & 3 \\
MK3 & Kardias & 90 & 7 & 3 \\
\hline
\end{tabular}

*Abbreviations: M: mixture; MEG:Megalopolis; P:Ptolemaidas; K: Kardias

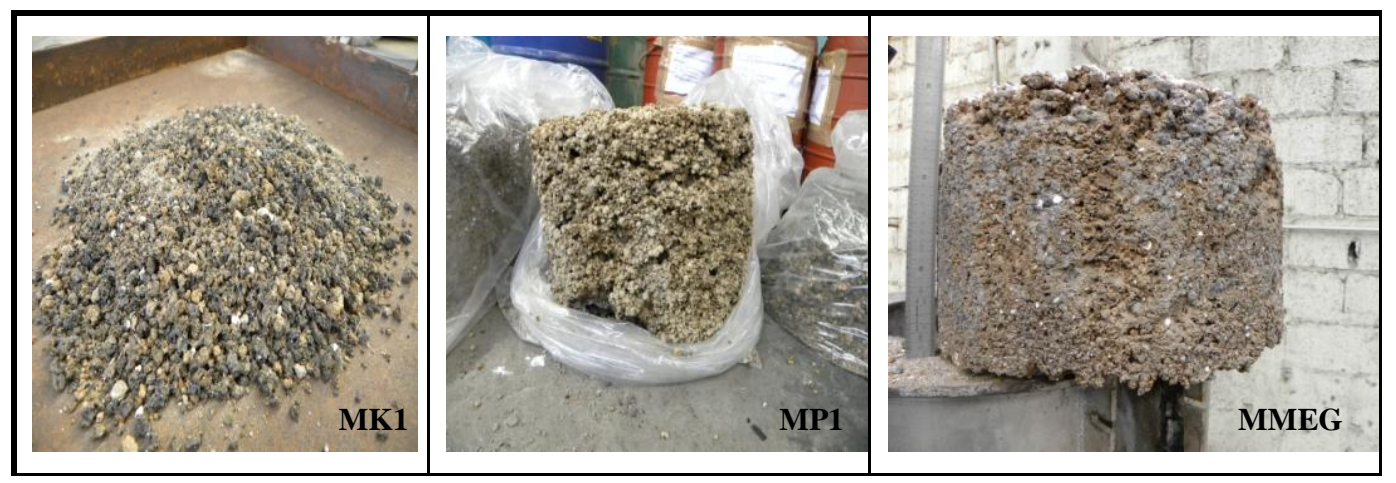

Figure 2 - Representative macroscopic images of sintered products.

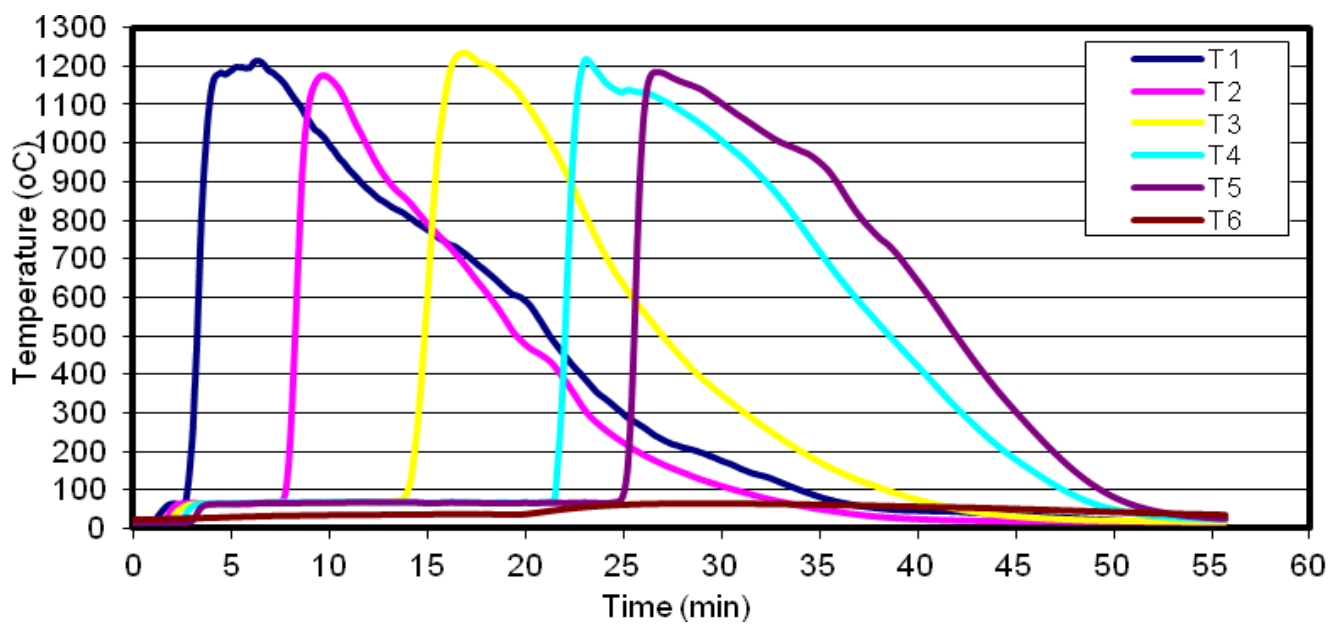

Figure 3 - Representative temperature -time diagram of sintering process (MMEG).

\subsubsection{Chemical Analyses and Physical Parameters}

The \%wt of major oxides in the sintered products are given in Table 3. As expected MMEG mixture is the most poor in $\mathrm{CaO}$ and the richer in $\mathrm{SiO}_{2}$, reflecting the chemistry of the raw materials. The maximum iron oxide has been analysed in MMEG sample. Minor oxides of $\mathrm{K}_{2} \mathrm{O}$ $(<2.16 \mathrm{wt} \%), \mathrm{MgO}(<2.89 \mathrm{wt} \%), \mathrm{Na}_{2} \mathrm{O}(<0.51 \mathrm{wt} \%), \mathrm{P}_{2} \mathrm{O}_{5}(<0.05 \mathrm{wt} \%), \mathrm{TiO}_{2}(<1.06 \mathrm{wt} \%), \mathrm{Cr}_{2} \mathrm{O}_{3}$ $(<0.04 \mathrm{wt} \%), \mathrm{CuO}(<0.29 \mathrm{wt} \%), \mathrm{MnO}(<1.19 \mathrm{wt} \%)$ and $\mathrm{ZnO}(<4.29 \mathrm{wt} \%)$ have been also determined. The low percentage of loss of ignition $(\max 1.6 \%$ in MP2) revealed that the incombustible $\mathrm{C}$ 
content of raw materials has been utilized as fuel well enough during the sintering process, promoting simultaneously the porous microstructure.

The results of physical parameter's measurements (apparent porosity, apparent specific gravity and water absorption) of products are displayed in Table 4. All samples except of MMEG and MK2, were broken down during the measurement (boiling). MMEG exhibited low apparent specific gravity $\left(0.89 \mathrm{~g} / \mathrm{cm}^{3}\right)$ while the MK2 $\left(1.43 \mathrm{~g} / \mathrm{cm}^{3}\right)$ higher than a commercial light aggregate one $\left(1 \mathrm{~g} / \mathrm{cm}^{3}\right)$. Additionally, MMEG exhibited higher percentage of water absorption and apparent porosity compared to MK2. The same Table contains the weights $(\mathrm{kg})$ of dry mixtures before and after sintering.

Table 3 - Chemical analyses of major oxides in the sintered products (wt \%).

\begin{tabular}{|l|c|c|c|c|}
\hline \multicolumn{1}{|c|}{ Sample } & $\mathbf{A l}_{2} \mathbf{O}_{\mathbf{3}}$ & $\mathbf{C a O}$ & $\mathbf{F e}_{\mathbf{2}} \mathbf{O}_{\mathbf{3}}$ & $\mathbf{S i O}_{\mathbf{2}}$ \\
\hline MMEG & 20.38 & 18.41 & 8.94 & 44.72 \\
\hline MP1 & 19.89 & 29.05 & 5.90 & 30.90 \\
MP2 & 21.14 & 25.07 & 5.95 & 32.25 \\
MP3 & 22.59 & 21.39 & 5.69 & 38.25 \\
\hline MK1 & 16.96 & 30.21 & 5.71 & 25.52 \\
MK2 & 17.41 & 26.92 & 5.53 & 27.04 \\
MK3 & 15.68 & 29.96 & 5.59 & 33.66 \\
\hline
\end{tabular}

Table 4 - Physical parameters of sintered products.

\begin{tabular}{|c|c|c|c|c|c|}
\hline $\begin{array}{c}\text { Physical } \\
\text { Parameters }\end{array}$ & $\begin{array}{c}\text { Apparent } \\
\text { porosity } \\
(\boldsymbol{\%})\end{array}$ & $\begin{array}{c}\text { Apparent } \\
\text { specific } \\
\text { gravity (g/cm }\end{array}$ & $\begin{array}{c}\text { Water } \\
\text { absorption } \\
(\boldsymbol{\%})\end{array}$ & $\begin{array}{c}\text { Dry weight be- } \\
\text { fore } \\
\text { sintering (kg) }\end{array}$ & $\begin{array}{c}\text { Weight after } \\
\text { sintering } \\
(\mathbf{k g})\end{array}$ \\
\hline Sample & & & & & \\
\hline MMEG & 59.7 & 0.89 & 67.5 & 33 & 19.6 \\
\hline MP1 & NM* & NM & NM & 30 & 19.4 \\
MP2 & NM & NM & NM & 27.5 & 21.25 \\
MP3 & NM & NM & NM & 25 & 18 \\
\hline MK1 & NM & NM & NM & 35 & 22 \\
MK2 & 42.8 & 1.43 & 30.2 & 32.5 & 12.7 \\
MK3 & NM & NM & NM & 32.5 & 13.5 \\
\hline
\end{tabular}

*Abbreviation: NM: not efficient for measurement

\subsubsection{XRD Analyses}

The semiquantitative mineralogical compositions of the sintered products are presented in Table 5 . The amorphous phase ranges from $~ 36$ (MK1) to $44 \mathrm{wt} \%$ (MP3) while anorthite, gehlenite and diopside (in two of them) are the major detected crystalline phases. It has been previously proved that in such materials, the mechanical strength is increased further by the anorthite appearance than the gehlenite (Anagnostopoulos, 2010). Samples MMEG, MP2 and MP3 contain the higher anorthite percentages ( $\sim 34-38 t \%)$ and the lower gehlenite $(\sim 3-9 \%)$, whilst the maximum diopside $(\sim 15 \%)$ is presented in MMEG, thus expected to improve further it's mechanical strength (Bethanis et. al, 2002). Moreover in MMEG most of the hematite has been reducted to the magnetite. Maximum amount of free lime has been detected in the MK3 sintered product. Its 
presence is undesired, since its subsequent transformation to portlandite by air humidity is accompanied by volume expansion resulting in disintegration of the solid matrix, making it unsuitable for further utilization. The different ratios of phases in the final products could be attributed to the combination of: 1) different geochemical/mineralogical compositions of BA and FA materials (as well as their lignite raw materials derived from), (Sakorafa et. al., 1996; Filippidis et. al., 1996; Siavalas et. al., 2009), 2) the sintering process, and 3) the different raw material ratios in the prepared mixtures. Moreover the chemically complicated systems of sintered products are reflected to their mineralogical compositions consisting of stable primary phases (eg quartz,) and new formed ones (eg diopside, magnetite) after different reactions mechanisms (decompositions, solid state reactions, reduction reactions, melting), not all in equilibrium conditions during the rapid sintering process (Anagnostopoulos, 2009).

\subsubsection{Microstructure by SEM}

SEM observations of final products revealed that all of them are characterized by a heterogeneous microstructure. Representative backscattered images are given in Figure 4. The MMEG sample exhibits the most compact structure because of the advanced sintering (via solid state reactions or melting phase bonding). Pores forming from outgassing are very often due to $\mathrm{C}, \mathrm{S}$ devolatilization, the structural destruction of Ca sulphates/ carbonates and iron oxide reduction. Pore sizes vary not only among the different samples but and in the structure of the same sample, due mainly to the extend grain variation of BA $(\sim 2-1000 \mu \mathrm{m})$. Porosity forming is accompanied with boating effect when the simultaneous mechanisms of melting on the grains surface, trapping gas inner, out gassing at high temperature are taking place, leading to the final lightweight products (Anagnostopoulos, 2009).

Table 5 - Semiquantitative (\%) analyses of major crystalline phases in the sintered products.

\begin{tabular}{|l|c|c|c|c|c|c|c|}
\hline \multicolumn{1}{|c|}{ Sample } & MMEG & MPI & MP2 & MP3 & MK1 & MK2 & MK3 \\
\hline Phases & 37 & 36 & 37 & 44 & 36 & 32 & 41 \\
\hline amorphous & $\operatorname{tr}$ & 1.5 & 1 & 1 & 1 & 1.5 & 1 \\
\hline anhydrite & 3 & 20 & 9 & 4 & 27 & 17 & 16 \\
\hline gehlenite & 1 & 7 & 7 & 2.5 & 5 & 5 & 6 \\
\hline $\begin{array}{l}\text { Dicalcium } \\
\text { silicate }\end{array}$ & 15 & 5 & 5 & 5 & 6 & 10.5 & 5 \\
\hline diopside & 36 & 26 & 34 & 38 & 22 & 25 & 21.5 \\
\hline anorthite & 4.5 & 2.5 & 3.5 & 3 & 2.5 & 6 & 4 \\
\hline quartz & 1 & - & - & - & $\operatorname{tr}$ & - & 2 \\
\hline $\begin{array}{l}\text { Hematite/ } \\
\text { magnetite }\end{array}$ & 2 & 1 & 1 & 1 & - & 1 & 1 \\
\hline $\begin{array}{l}\text { Brawn } \\
\text { millerite }\end{array}$ & 1 & 1 & 1 & 1.5 & $\operatorname{tr}$ & 2 & 2 \\
\hline $\begin{array}{l}\text { Lime/ } \\
\text { Portlandite }\end{array}$ & - & $\operatorname{tr}$ & $\operatorname{tr}$ & $\operatorname{tr}$ & $\operatorname{tr}$ & - & 1 \\
\hline
\end{tabular}



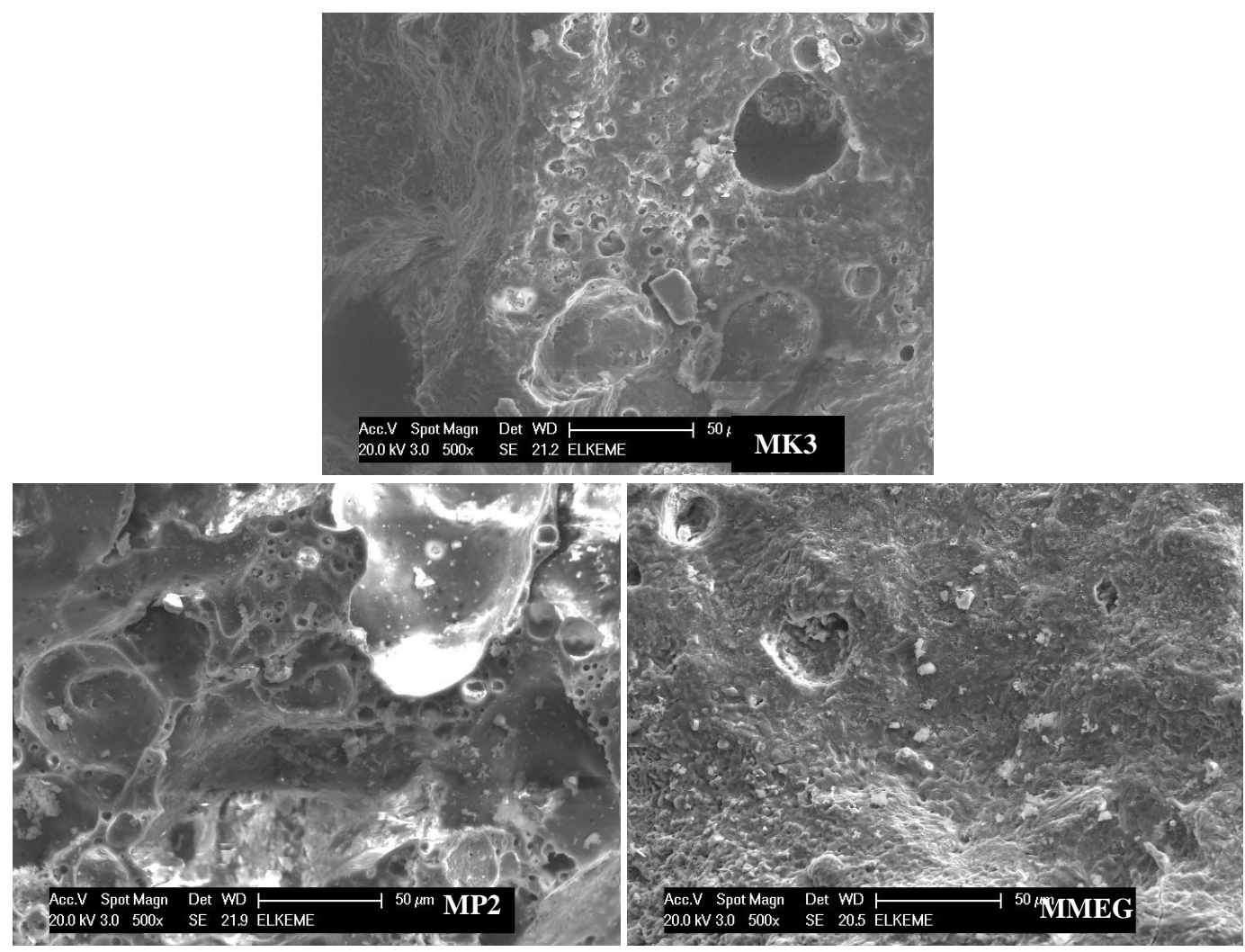

Figure 4 - Representative backscattered images of sintered products.

\section{Conclusions}

The bottom ashes from Kardia, Ptolemaida and Megalopoli regions contain the demanded incombustible $\mathrm{C}$ for its utilization as fuel during the sintering process (till $1200^{\circ} \mathrm{C}$ ) by the sinter band method. The final mineneralogical compositions of sintered products reflecting the complicated mechanisms have taken place during the rapid sintering, leading to the boaming effect and porous structures. The higher $\mathrm{SiO}_{2}$ content of MMEG is believed to be essential for the evolution of the sintering process by participation in the formation of crystalline phases which enhance bonding and lead to the production of the desired sinter-cake. Presence of free lime in the sintered products is undesired, since its subsequent transformation to portlandite by air humidity is accompanied by volume expansion resulting in disintegration of the solid matrix, making it unsuitable for further utilization. According to the macroscopic characterization, the physical properties as well as the mineral compositions and microstructures, the MMEG sintered mixture could be characterized as a light aggregate material and it is proposed as suitable for further treatment in the lightweight concrete production.

\section{Acknowledgments}

The authors are grateful for the XRD investigations of fly ashes, bottom ashes and sintered products carried out by Professor Dr. G. Kostakis, Laboratory of Applied Mineralogy, Technical University of Crete, Hania. Professor Dr. Manoutsoglou Emmanuil, Editor; and reviewers, Dr. S. Kalaitzidis and Dr. Koukouzas, are thanked for comments and suggestions which improved the previous version of the manuscript. 


\section{References}

Anagnostopoulos I. M. and Stivanakis V.E. 2009. Utilization of lignite power generation residues for the production of lightweight aggregates, J. Hazard. Mater., 163, 329-336.

Anagnostopoulos I. 2009. Utilization of lignite power generation residues for the production of lightweight aggregates and lightweight concrete, PhD Thesis, University of Patras, Greece.

Anagnostopoulos I.M., Stivanakis V.E., Angelopoulos, G.N. and Papamantellos D.C. 2010. Valorization of lignite combustion residues and ferroalumina in the production of aggregates, J. Hazard. Mater., 174, 506-511.

ASTM C373-88 2002. Standard test method for water absorption, bulk density, apparent porosity and apparent specific gravity of fired whiteware products, Annual Book of ASTM standards, USA.

Bethanis S., Cheeseman C. R. and Sollars C.J. 2002. Properties and microstructure of sintered incinerator bottom ash, Ceram. Int., 28, 881-886.

Bhatty J.J. and Reod K.J. 1989. Lightweight aggregates from incinerated sludge ash, Waste Manag. Res., 7, 363-376

Cheeseman C.R., Makinde A. and Bethamis S. 2005. Properties of lightweight aggregates produced by rapid sintering of incinerator bottom ash, Resour. Conserv. Recy., 45, 147-162.

Filippidis A., Georgakopoulos A. and Kassoli-Fournaraki A. 1996. Mineralogical components of some thermally decomposed lignite and lignite ash from the Ptolemais basin, Greece, Int. J. Coal Geol. 30 (4), 303-314.

Lin K.L. 2006. Feasibility study of using brick made from municipal solid waste incinerator fly ash slag, J Hazard Mater., 137(3), 1810-6.

Nishigaki M. 2000. Producing permeable blocks and pavement bricks from molten slag, Waste Manage, 20(2-3), 185-92.

Vegas I., Ibañez J.A., San José J.T. and Urzelai A. 2008 Construction demolition wastes, Waelz slag and MSWI bottom ash: a comparative technical analysis as material for road construction, Waste Manage, 28(3), 565-74.

Sakorafa V., Michailidis K. and Burragato F. 1996. Mineralogy, geochemistry and physicalproperties of fly ash from the Megalopolis lignite fields, Peloponnese, Southern Greece, Fuel, 75(4), 419-423.

Siavalas G., Linou M., Chatziapostolou A., Kalaitzidis S., Papaefthymiou H. and Christanis K 2009. Palaeoenvironment of Seam I in the Marathousa Lignite Mine, Megalopolis Basin (Southern Greece), Int. J. Coal Geol., 78 (4), 233-248. 